\title{
EJAI NA AMAZÔNIA PARAENSE: ataques e resistências na luta pela educação pública e gratuita
}

\author{
Maria da Conceição dos Santos Costa \\ Maria Celeste Gomes de Farias \\ Darinếz de Lima Conceição
}

\section{Resumo}

O estudo objetiva analisar a Educação de Jovens, Adultos e Idosos (EJAI) por meio das orientações dos organismos multilaterais, apresentando dados concretos da realidade da Amazônia Paraense e estratégias de resistências construídas com os movimentos sociais em defesa desta modalidade de educação. A metodologia adotada teve como base o materialismo histórico dialético e o uso da análise documental e de dados oficiais do INEP. Os resultados evidenciam ataques à EJAI com grande redução de atendimento devido à diminuição de matrículas e fechamento de turmas. Concluímos que os movimentos sociais são resistências de enfrentamento na luta e defesa da EJAI, direito inalienável dos diversos sujeitos da Amazônia Paraense à educação pública, gratuita e socialmente referenciada.

Palavras-chave: educação de jovens; adultos e idosos; amazônia paraense; resistências.

EJAI IN THE PARAENSE AMAZON: attacks and resistance in the struggle for public and free education

\section{Abstract}

The study aims to analyze the Education of Youth, Adults and the Elderly (EJAI). Through the guidelines of multilateral organizations, it presents concrete data of the Paraense Amazon, as well as strategies of resistance built with social movements in advocacy of this modality of education. The methodology adopted was based on historical dialectical materialism and uses documentary analysis of official data from INEP (National Institute for Educational Studies and Research). The results show offensives against EJAI which have originated a great reduction in attendance and decrease in enrollment, besides cause closing of classes. It was concluded that social movements represent forms of resistance and confrontation in advocacy of EJAI as an inalienable right of the diverse subjects of the Paraense Amazon to public education, free and socially referenced.

Keywords: youth adult and elderly education; paraense amazon; resistances.

\section{EJAI EN LA AMAZONÍA PARAENSE: ataques y resistencia en la lucha por la educación gratuita}

Resumen

El estudio tiene como objetivo analizar la Educación de Jóvenes, Adultos y Ancianos (EJAA) a través de las directrices de las organizaciones multilaterales, presentando datos concretos sobre la realidad de la Amazonía Paraense y las estrategias de resistencia construidas con movimientos sociales en defensa de este tipo de educación. La metodología adoptada se basó en el materialismo dialéctico histórico, utilizando análisis documentales y datos oficiales del INEP. Los resultados muestran ataques al EJAA con una gran reducción de asistencia a través de la reducción de inscripciones y cierre de clases. Concluimos que los movimientos sociales son resistencias de confrontación en la lucha y defensa de EJAA como un derecho 
DOI: $10.12957 /$ teias. $\%$ Y.50113

inalienable de los diversos sujetos del Amazonas Paraense a la educación pública, gratuita y socialmente referenciada.

Palabras clave: educación de jóvenes; adultos y ancianos; paraense amazonas; resistencias

\section{INTRODUÇÃO}

Este estudo trata da Educação de Jovens, Adultos e Idosos (EJAI) na Amazônia Paraense, nas redes de ensino do Estado do Pará e seus municípios. Ele surge em conexão com as vivências como pesquisadoras da EJAI e como membros do Movimento Paraense de Educação de Jovens e Adultos (MPEJA); e é forjado enquanto resistência em defesa da educação pública, gratuita e socialmente referenciada aos sujeitos desta modalidade de educação na escola pública na Amazônia Paraense.

A EJAI é compreendida enquanto modalidade de educação formada pelos diversos sujeitos integrantes da classe trabalhadora, tais como: jovens, adultos e idosos da cidade, do campo, das comunidades ribeirinhas, das florestas, das águas, dos assentamentos, das comunidades indígenas e quilombolas e dos sistemas prisionais, que, no contexto desta investigação, vivem seus processos de luta pela dignidade à vida, à educação pública, à saúde pública, ao saneamento, ao lazer, ao trabalho, dentre outros, direito ontológico para a construção da humanidade em diálogo permanente com o ser forjado no território Amazônico Paraense. Para Oliveira e Hage (2011), a Amazônia Paraense se caracteriza por grande diversidade socioterritorial, que compreende os territórios do campo, com uma multiplicidade de populações, e da cidade, que integram a complexa teia de relações sociais, econômicas e culturais.

No que tange à compreensão de território, alinhamo-nos ao exposto por Santos (1999, p. 07) ao defender que, "[...] território é o lugar em que desembocam todas as ações, todas as paixões, todos os poderes, todas as forças, todas as fraquezas, isto é, onde a história do homem plenamente se realiza a partir das manifestações da sua existência".

A territorialidade dos sujeitos que integram a EJAI apresenta-se como reflexo da diversidade sociocultural histórica na Amazônia. A heterogeneidade, como destaca Paiva, Machado e Ireland (2007, p. 29), é inerente ao processo educativo nesta modalidade de educação, quer seja no campo escolar ou não escolar, em territórios do campo ou da cidade. A heterogeneidade sociocultural dos indivíduos, a diversidade de suas demandas educativas e de suas condições de estudo e aprendizagem requerem respeito às especificidades das zonas urbanas e rurais e à pluralidade cultural, de gênero, étnica e religiosa da população brasileira, considerando as características psicossociais, os ritmos, as aspirações, as projeções e os interesses próprios dos educandos. Os programas de EJAI devem ser flexíveis nas formas de atendimento, de modo a garantir a pluralidade de concepções pedagógicas e metodológicas e o respeito às especificidades na seleção dos materiais didáticos e na organização do ambiente escolar (PAIVA, MACHADO, IRELAND, 2007). A flexibilidade do atendimento na escola deve considerar a realidade da classe trabalhadora dos sujeitos integrantes da EJAI - que vivem do trabalho (ANTUNES, 2005) ou que dependem de outrem que concretamente vive do trabalho.

Este artigo apresenta como problemática: qual o contexto da EJAI no território da Amazônia Paraense e quais os impactos dos desmontes que, esta modalidade, em especial, vem enfrentando na atual conjuntura do Brasil? Nessa direção, o objetivo é analisar os reflexos das orientações dos organismos internacionais sobre a EJAI, considerando os dados concretos da realidade da Amazônia Paraense e as estratégias de resistências construídas com os movimentos 
sociais em defesa da EJAI, enquanto um direito inalienável de jovens, adultos e idosos à educação pública, gratuita e socialmente referenciada.

A metodologia adotada tem como base o materialismo histórico dialético, o que permitiu compreender o fenômeno EJAI como totalidade concreta da realidade na Amazônia Paraense, examinando-o "[...] como um todo estruturado, dialético, no qual ou do qual um fato qualquer [...] pode vir a ser racionalmente compreendido" (KOSIK, 1976, p. 35). Analisa-se os dados a partir de categorias como totalidade, contradição e mediação (BOTTOMORE, 1988), evidenciadas no discurso do Estado brasileiro; este discurso é amparado nas orientações dos organismos internacionais para a ausência de políticas públicas educacionais e justifica a negação do direito à educação à classe trabalhadora que precisa acessar a EJAI na Amazônia Paraense.

Fizemos uso da análise documental por meio dos documentos produzidos pela Organização das Nações Unidas para Educação, a Ciência e a Cultura (Unesco) e pelo Banco Mundial, em busca de compreender a "hegemonia discursiva", a ideologia, a lógica e a racionalidade que sustentam os interesses do capital (SHIROMA et al., 2005, p.430) mediante a educação, em especial a EJAI; nos amparamos a princípio na pesquisa qualitativa, a partir da análise de dados oficiais dos Microdados do Censo Escolar do Instituto Nacional de Estudos e Pesquisas Educacionais Anísio Teixeira (INEP), referentes ao números de turmas e ao total de matrículas entre os anos de 2013 e 2019 nas redes de ensino do estado do Pará e municípios. Esta análise evidenciou a grande redução de atendimento à EJAI por meio da diminuição de matrículas e do fechamento de turmas de nos 144 municípios paraenses. Também realizamos levantamento dos registros das ações do coletivo MPEJA que denuncia o fechamento de turmas e a diminuição de matrícula da EJAI nos últimos anos na Amazônia Paraense, como estratégia de luta e resistência em defesa da EJAI.

Evangelista (2009, p. 01) destaca que é necessário compreender o que está por trás do discurso, pois documentos oficiais revelam conflitos, litígios, veemências, projetos políticos, história, expressam diretrizes, articulam um conjunto de interesses e produzem intervenções sociais, tais como documentos oficiais, dados estatísticos, leis, relatórios, dentre outros.

O texto apresenta, num primeiro momento, reflexões sobre a EJAI e as orientações advindas dos organismos internacionais; posteriormente, apresentamos dados sobre a EJAI na Amazônia Paraense; socializamos as resistências construídas por meio do MPEJA em torno da EJAI nas redes de ensino e, por fim, tecemos considerações finais.

\section{A EJAI NO CONTEXTO DOS ORGANISMOS MULTILATERAIS}

A educação nas últimas décadas se tornou o epicentro da agenda social, política e econômica em países desenvolvidos e subdesenvolvidos. Shiroma e Evangelista (2014) destacam que, na sociedade capitalista, a educação vem sofrendo os determinantes do capital e recebe status de "lugar" que irá "solucionar" os problemas econômicos, sociais, culturais de toda sociedade. As autoras salientam que a educação em seu sentido geral vem apresentando práticas, estratégias, compromissos que materializam a manutenção do sistema capitalista contemporâneo, perpetuando ideologicamente as demandas da produção e reprodução deste.

A EJAI, em seu amparo regulador no Brasil, assentada conforme a Lei de diretrizes e bases da educação nacional (LDB) 9394/96, ainda não representa o conjunto da classe trabalhadora da EJAI. O acesso, a gratuidade e as condições de permanência devem ser o tripé condicional para jovens, adultos e idosos na escola pública, pois isto representa justiça aos que foram 
historicamente excluídos da educação pública, gratuita e socialmente referenciada. É fazer justiça à classe trabalhadora, ao direito inalienável de ter acesso aos conhecimentos construídos pela humanidade em relação a todas as áreas de conhecimento e suas relações com o mundo do trabalho, numa perspectiva crítica, criativa e emancipadora (FREIRE, 2011).

A Unesco (2015) em seu documento "Declaraşão de Incheon - Educação 2030: rumo a uma educação de qualidade inclusiva e equitativa e à educação ao longo da vida para todos", organizado por meio do Fórum Mundial de Educação (2015), apresenta a visão de transformar vidas por meio da educação, reconhecendo esta como uma importante impulsionadora para o desenvolvimento dos países desenvolvidos e subdesenvolvidos. O objetivo central é: "Assegurar a educação inclusiva e equitativa de qualidade, e promover oportunidades de aprendizagem ao longo da vida para todos" (UNESCO, 2015, p. 01) e mais, a educação é colocada como a "principal" responsável pelo emprego e pela erradicação da pobreza, assim como pelos resultados da aprendizagem ao longo da vida.

A educação não pode ser responsabilizada pela condição de acesso ao "emprego" e pela "erradicação da pobreza", e nem pode ser atrelada à lógica do mercado como parece apontar a Unesco. As políticas que visam ao desenvolvimento da previdência social, do lazer, da segurança, da saúde, dentre outras áreas vitais para o viver humano - nas áreas econômicas, sociais, culturais, educacionais, do trabalho - devem estar integradas numa perspectiva multiprofissional e ontológica, que considera o trabalho como centralidade da vida e existência humana para o desenvolvimento de todas as suas capacidades biológicas-sociais-culturais-corporais-técnicas para o pleno desenvolvimento humano. O trabalho é categoria fundante da sociabilidade humana, como aponta Engels (2013). Sendo uma condição fundamental e básica da vida humana, o trabalho proporciona o desenvolvimento do próprio homem.

No mesmo documento, a Unesco (2015) aponta:

[...] oportunidades de educação ao longo da vida para todos, em todos os contextos e em todos os níveis de educação; [...] a validação e a certificação do conhecimento, das habilidades e das competências adquiridos por meio tanto da educação formal quanto da educação informal; [...] garantir que todos os jovens e adultos, especialmente as meninas e as mulheres, alcancem níveis de proficiência em habilidades básicas em alfabetização e matemática, que sejam relevantes e reconhecidos, adquiram habilidades para a vida e tenham oportunidades de aprendizagem, educação e formação na vida adulta [...] (p. 02)

A concepção da "educação ao longo da vida para todos" propagada pela Unesco está assentada na lógica da competitividade e no ato de "aprender para ganhar", aspectos condicionantes da sociedade capitalista. A busca por "[...] níveis de proficiência em habilidades básicas em alfabetização e matemática" está relacionada à formação de mão-de-obra barata para o mercado de trabalho; tal enunciado tem correlação com a concepção da Unesco de educação alinhada à busca pelo "emprego" e pela "erradicação da pobreza", colocando a educação na condição de "salvadora" dos problemas da sociedade contemporânea. É necessário que a educação seja assentada para as práticas democráticas e de justiça a todos os sujeitos da sociedade, sem distinção de classe, gênero, etnia, dentre outros, a fim de que a formação possa se materializar em comunhão de todos (as), em diálogo permanente (FREIRE, 2012) e na superação do antagonismo opressor-oprimido.

Para Ventura (2008, p. 240), a EJAI, neste cenário, atua no processo de “[...] ajustes de sujeitos para o trabalho simples, adequando e ajustando às novas [...] exigências econômicas, 
sociais e políticas do capitalismo brasileiro associado e subalterno ao internacional". Jovens, adultos e idosos são considerados, na oferta educacional, sujeitos circunscritos para "receber" “[...] saberes mínimos necessários para a execução de tarefas simples e de baixíssima complexidade na nova divisão do processo de trabalho capitalista, ao mesmo tempo aliviando-os da situação de extrema pobreza" (VENTURA, 2008, p. 240).

O documento "Atingindo uma educação de nivvel mundial no Brasil: Próximos Passos" (BRUNS, EVANS, LUQUE, 2011), organizado pelo Banco Mundial, apresenta um debate sobre a educação no Brasil mediante os resultados das avaliações em larga escala, como por exemplo o PISA (Programa Internacional de Avaliação de Estudantes) e o teste da OCDE (Organização para a Cooperação e Desenvolvimento Econômico), que "[...] medem o nível de aprendizagem de estudantes de ensino médio em mais de 65 países [...]"(BRUNS, EVANS, LUQUE, 2011, p. 01). Realizado a cada três anos para medir o desempenho dos estudantes na faixa etária dos 15 anos, em relação aos conhecimentos e habilidades (em matemática, leitura e ciências) daqueles em relação a outros países; sua intenção também é impactaras políticas e os programas educacionais nos países participantes dessa avaliação (INEP, 2019).

Segundo Bruns; Evans e Luque (2011), o Brasil está longe de alcançar os níveis médios de aprendizagem, as taxas de conclusão do ensino médio e a eficiência de fluxo estudantil dos países da OCDE e de outros países de renda média. A lógica posta é da hegemonia das avaliações em larga escala para ranqueamento entre os países, as instituições e os sujeitos, sem levar em consideração os seguintes pontos: as condições objetivas e subjetivas do trabalho docente nas escolas públicas; os docentes que atuam com jornadas de trabalho exaustivas para "sobreviver na docência", assumindo cargas horárias e diversas turmas para ganhar um salário que não é digno na carreira docente, tendo em vista que muitos estados do Brasil não pagam o piso salarial. As escolas não possuem condições de trabalho dignas para o exercício da docência e o processo de apropriação e a experiência dos estudantes com uso de materiais didáticos, laboratórios, ginásios, salas de aulas confortáveis - dentre outros que favoreçam a aprendizagem no tempo escolar não são uma realidade nas escolas da cidade e do campo no Brasil.

E qual o lugar da EJAI diante do conjunto de práticas, programas e políticas orientados pelos organismos multilaterais? A seguir, apresentamos um excerto que se refere aos sujeitos da EJAI:

Estima-se que $44 \%$ dos estudantes brasileiros do ensino secundário são, pelo menos, dois anos mais velhos que a idade recomendada para sua série. E 15\% de todos os concluintes desse ciclo possuem mais de 25 anos -7 anos atrás da idade oficial prevista para conclusão. Nenhum desses padrões é observado em outros países da ALC, outros países em desenvolvimento, ou países da OCDE (BRUNS, EVANS, LUQUE, 2011, p. 75).

O tempo, as condições de acesso e de permanência com qualidade na educação pública não são debatidos nos documentos acima para os sujeitos que estão na escola pública, tanto da Unesco quanto do Banco Mundial. A prioridade vem sendo em avaliações de larga escala, com centralidade em matemática, português e ciências. Para fortalecer o Índice de Desenvolvimento da Educação Básica (IDEB), por exemplo, temos a prova ANA (Avaliação Nacional de Alfabetização), na educação infantil, a prova BRASIL (que passa a ser chamada de Saeb dos anos finais do ensino fundamental), o ENEM (Exame Nacional de Ensino Médio) no ensino médio; a adequação idade-série no tempo escolar não condiz com a realidade concreta dos sujeitos da 
EJAI que são oriundos da classe trabalhadora e precisam do trabalho para sobreviver nesta complexa e contraditória sociedade capitalista.

O mesmo documento trata do desempenho das escolas e das condição de evasão, aspecto que também faz parte da realidade da EJAI, pois os sujeitos trabalhadores precisaram ou precisam abrir mão da função de estudantes para ocupar a função de trabalhadores (as); este documento considera as escolas públicas secundárias como "fábricas de evasão"; e acusa os estudantes brasileiros de não desistirem, de insistirem em concluir o ensino médio, em que pese as repetições até a idade adulta (BRUNS, EVANS, LUQUE, 2011, p. 76).

Os estudantes brasileiros são oprimidos por um sistema educacional que ainda não pensou o currículo, as metodologias, a escola, a organização pedagógico-administrativa, os tempos e os espaços para acolher os estudantes e instrumentalizar dignas condições de acesso aos conhecimentos historicamente construídos pela humanidade, e para que estes tenham relação ontológica com o mundo do trabalho, com a cultura, com o território na cidade e no campo, ou seja, na sociedade em que vivemos. Em que pese a caracterização das escolas públicas secundárias do Brasil de "fábricas de evasão", pelo Banco Mundial, são essas escolas que têm sido o único, senão exclusivo, espaço educativo público e gratuito para o conjunto da classe trabalhadora brasileira; nesses espaços, crianças, jovens, adultos e idosos ocupam as cadeiras e lutam por conhecimento e por uma aprendizagem significativa para suas vidas.

É evidente a desumanização (FREIRE, 2012) presente nas análises do Banco Mundial, o julgamento e o preconceito com os estudantes, sujeitos que precisam da educação pública; estes lutam, não desistem de ter acesso à educação, independentemente da idade adulta, pois aprender, conhecer e experimentar são direitos inalienáveis de todos os sujeitos, quer sejam da EJAI ou de outras modalidades e etapas da educação. Freire (2012) destaca que os sujeitos oprimidos lutam pela humanização do trabalho livre, pela desalienação e pela afirmação dos homens como pessoas, para a construção de outra sociabilidade autodeterminada, justa e fraterna.

No contexto acima exposto, a EJAI é um obstáculo para as avaliações em larga escala; é um "transtorno" para os índices avaliativos e ranqueadores das avaliações no Brasil e para as regiões que apresentam características diversas em relação à economia, ao trabalho, à cultura, à educação, à saúde, ao lazer, à segurança, ao transporte, dentre outros. Para o Banco Mundial, o "progresso do Brasil" está circunscrito a áreas críticas que devem ser trabalhadas, como equalização do financiamento da educação; medição dos resultados e transferências condicionais de recursos financeiros para aumentar o nível de escolaridade da população de baixa renda (BRUNS, EVANS, LUQUE, 2011). Aspecto que não é mediado pelo acesso ao trabalho, aos bens necessários como saúde, segurança, transporte, cultura, lazer, dentre outros, de caráter público e gratuito para todos, bem como a distribuição de renda num país extremamente desigual e injusto.

No relatório de monitoramento global da educação de 2019 (UNESCO, 2019), que trata de migração, deslocamento e educação, destacamos o campo que trata da diversidade. Neste, a educação é preconizada pela valorização da diversidade, que deve ser materializada para todos os países a fim de construir sociedades inclusivas, nas quais as diferenças são respeitadas; o preconceito e a discriminação presentes nos sistemas educacionais devem ser combatidos. Contraditoriamente, não discute a especificidade dos sujeitos que integram os sistemas educacionais, pois estes representam o conjunto da sociodiversidade existente no Brasil, na Amazônia e nas demais regiões não somente do país, mas dos demais países do mundo. Muito menos, não problematiza as avaliações de larga escala e as condições objetivas e subjetivas dos 
sujeitos que participam desses processos, excludentes e discriminatórios; ainda sim, não pauta a especificidade da EJAI enquanto uma modalidade de educação, direito de todos os sujeitos que precisam ter acesso à educação pública, pois a centralidade da EJAI para os organismos multilaterais é "abolir" do sistema educacional, pois a quais interesses respondem a EJAI diante da lógica hegemônica das avaliações em larga escala?

Notamos que os documentos norteadores das políticas, das práticas e dos programas dos organismos multilaterais, aqui em destaque, Unesco e Banco Mundial, não coadunam com a realidade concreta do Brasil, no campo da EJAI, enquanto estratégia política de enfrentamento aos desafios da EJAI no contexto brasileiro. Muito menos no que tange ao Plano Nacional de Educação (2014) quanto à elevação da taxa de alfabetização da população com 15 anos e, até o final da vigência deste PNE, erradicar o analfabetismo absoluto e reduzir em 50\% a taxa de analfabetismo funcional. Estamos longe de enfrentamentos concretos por parte do Estado brasileiro em defesa da EJAI, enquanto direito político, social e humanizador para os sujeitos que integram esta modalidade de educação. A seguir, vamos ver como a desumanização vem se materializando em formas de ataques e expropriação dos sujeitos da EJAI na Amazônia Paraense.

\section{O CENÁRIO DA EJAI NA AMAZÔNIA PARAENSE: REDUÇÃO DE ATENDIMENTO QUE NEGA O DIREITO À EDUCAÇÃO.}

O Estado do Pará ou a Amazônia paraense - como estamos denominando em seu processo histórico de formação no território da maior floresta tropical do mundo - é caracterizado por Hage e Barros (2010) com identidades/subjetividades que representam suas especificidades, ou, no dizer de Porto Gonçalves (2005), Amazônias; é identificado por uma heterogeneidade ambiental com a variedade de ecossistemas complexos e ricas teias de biodiversidade, e apesar da devastação ainda preserva grande área da floresta com $20 \%$ da disponibilidade de água doce do mundo.

A Amazônia paraense também possui uma grande heterogeneidade produtiva, onde coexistem lógicas e práticas divergentes e opostas com atividades econômicas de base familiar, cooperadas e o uso de tecnologias simples; como também possui processos de produção capitalista, em larga escala, com uso de sofisticadas e complexas tecnologias no domínio dos produtores de base do agronegócio - como os grandes pecuaristas, nos megaprojetos como o complexo de Carajás, a hidrelétrica de Belo Monte. Isso demarca um desenvolvimento econômico em que protagonizam a colonização pela exploração sem precedentes, que cada vez mais parece fortalecer-se com a travessia do tempo. Para Pinto (2012, p. 26), esse processo "[...] obedece ao velho esquema colonial. Integração e desenvolvimento significam, na verdade, submissão da terra e do homem às determinações do agente externo". A heterogeneidade sociocultural do território da Amazônia paraense é constituída de caboclos, ribeirinhos, pescadores, extrativistas, indígenas e quilombolas, migrantes de outras regiões brasileiras e estrangeiros, agricultores familiares, assentados, sem terra, sem teto, atingidos por barragem, segmentos populares (idosos, deficientes, jovens, crianças, mulheres, negros, trabalhadores, dentre outros), fazendeiros, madeireiros, latifundiários, grandes produtores rurais. Assim, a EJAI na Amazônia paraense é diversa no aspecto político, social, cultural e populacional e demanda que as políticas e as práticas educacionais considerem tal diversidade e afirmem as identidades e modos de vida próprios das Amazônias (GONÇALVES, 2005). 
O contexto heterogêneo da EJAI não se coaduna com as orientações advindas dos organismos internacionais para o Estado brasileiro, que padroniza as políticas e as avaliações educacionais em larga escala e desconsidera as realidades específicas nas quais a EJAI se manifesta. As ações das redes de ensino estadual e municipais, ao se orientarem pelos organismos externos, acabam agindo na contramão da riqueza de sua sociobiodiversidade; pactuamos com Conceição (2016, p. 125), ao destacar que o Pará segue o fluxo do direcionamento econômico do capital, no fortalecimento e na manutenção da baixa formação dos sujeitos da cidade e do campo, para fins de recomposição de mão de obra barata, "[...] forma-se assim, então, um exército de trabalhadores adaptados e com baixíssimo custo para a manutenção do capital.

A negação do direito à educação aos sujeitos da EJAI na Amazônia paraense se expressa, por exemplo, por meio do fechamento de turmas e pela diminuição de matrículas nessa modalidade de ensino. Para demonstrarmos a realidade de atendimento da EJAI no território da Amazônia Paraense, nas redes de ensino estadual e municipal, realizamos o levantamento na base de dados INEP. No que tange à quantidade de turmas que tais redes ofertaram nos últimos sete anos (2013 a 2019) nas etapas do ensino fundamental e médio, apresentamos a Tabela 1 abaixo:

Tabela 1: Total número de turmas, dependência administrativa (estadual e municipal). EJA ensino fundamental e médio, Pará - 2013 a 2019

\begin{tabular}{|c|c|c|c|c|c|c|c|}
\hline Etapa/ano & 2013 & 2014 & 2015 & 2016 & 2017 & 2018 & 2019 \\
\hline Fundamental & 7.447 & 6.830 & 6.157 & 5.318 & 5.010 & 4.660 & 4.285 \\
\hline Médio & 1.408 & 1.433 & 1.502 & 1.417 & 1.313 & 1.219 & 1.145 \\
\hline Total & 8.855 & 8.263 & 7.659 & 6.735 & 6.323 & 5.879 & 5.430 \\
\hline
\end{tabular}

Fonte: Microdados do Censo Escolar/INEP 2013 - 2019

$\mathrm{Na}$ análise da Tabela 1 podemos perceber que no ensino fundamental o total de turmas correspondia a 7.447 em 2013, sendo reduzidas para 4.285 em 2019. Por sua vez, a EJAI ensino médio era de 1.408 em 2013 passando para 1.145 em 2019. Assim, a soma da redução de números de turmas nas duas etapas de ensino (fundamental e médio) nas esferas administrativas (estadual e municipal) nos últimos cinco anos é 3.425. Desse total, cerca de 3.162 de turmas fechadas são de ensino fundamental e 263 são de ensino médio, o que representa em percentual $38,68 \%$ de turmas fechadas nas duas etapas de ensino.

A Tabela 2, abaixo, nos mostra o quantitativo de turmas envolvendo a EJAI de ensino fundamental e médio somente na rede estadual.

Tabela 2: Total de número de turmas, dependência administrativa estadual, EJAI, ensino fundamental e médio, Pará, 2013 - 2019

\begin{tabular}{l|r|r|r|r|r|r|r}
\hline Etapa/ano & 2013 & 2014 & 2015 & 2016 & 2017 & 2018 & 2019 \\
\hline Fundamental & 1.423 & 1.379 & 1.274 & 1.102 & 942 & 851 & 771 \\
\hline Médio & 1.405 & 1.431 & 1.497 & 1.409 & 1.307 & 1.212 & 1.141 \\
\hline Total & 2.828 & 2.810 & 2.771 & 2.511 & 2.249 & 2.063 & 1.912 \\
\hline
\end{tabular}

Fonte: Microdados do Censo Escolar/INEP 2013-2019 
$\mathrm{Na}$ rede estadual, os dados da Tabela 2 demostram que o atendimento de números de turmas de EJAI no ensino fundamental fora reduzido de 1. 423 em 2013 para 771 em 2019, totalizando 652 turmas fechadas em sete anos. Acompanhando a tendência de redução, o número de turmas do ensino médio caiu de 1.405 para 1.141 em 2019, o que representa 264 turmas fechadas. Nesse sentido, o total de turmas envolvendo o ensino fundamental e médio na esfera do estado passa de 2.828 em 2013 para 1.912, evidenciando uma redução de 916 turmas em sete anos, o que representam em percentuais cerca de $32,39 \%$.

Já a Tabela 3, abaixo, nos mostra os dados de números de turmas somente nas redes municipais, envolvendo os 144 municípios paraenses.

\section{Tabela 3: Total número de turmas, dependência administrativa municipal, EJAI, ensino} fundamental e médio, Pará, 2013 - 2019

\begin{tabular}{l|l|l|l|l|l|l|l}
\hline Etapa/ano & 2013 & 2014 & 2015 & 2016 & 2017 & 2018 & 2019 \\
\hline Fundamental & 6.024 & 5.451 & 4.883 & 4.216 & 4.068 & 3.809 & 3.514 \\
\hline Médio & 3 & 2 & 5 & 8 & 6 & 7 & 4 \\
\hline Total & 6.027 & 5.453 & 4.888 & 4.224 & 4.074 & 3.816 & 3.518 \\
\hline
\end{tabular}

Fonte: Microdados do Censo Escolar/2013-2019

As análises dos dados da Tabela 3 nos mostram que o total de números de turmas no ensino fundamental que, em 2013, era de 6.024, passa para 3.514 em 2019, representando um total de 2.510 de turmas fechadas em sete anos. Isso significa, em percentuais, cerca de 41,62\% de turmas a menos. No ensino médio, embora não seja competência prioritária da esfera municipal, observa-se que o número de turma passou de três, em 2013, para quatro, em 2019, e oscilou entre os anos de 2015 a 2018.

A análise de fechamento de turmas de EJAI na Amazônia paraense, nas redes de ensino estadual e municipal a partir dos dados oficiais do INEP, nos mostra uma realidade que acompanha o contexto da EJAI em quase todo o Brasil. De 2009 a 2019, o país reduziu em cerca de um terço o número de escolas que ofertavam EJA no ensino fundamental, numa variação nacional de menos 34\%, envolvendo os estados da federação; somente o Distrito Federal apresentou um aumento de $8,8 \%$ de escolas que no mesmo período passaram a ofertar EJA (MORENO, 2019).

A princípio, a redução de escolas e o fechamento de turmas de EJAI, no contexto da Amazônia paraense, poderia ser algo positivo, pois levaria a supor que o estado do Pará ampliou o atendimento nas demais etapas de ensino e, consequentemente, a demanda pela EJA estaria diminuindo. Porém, quando comparamos com a faixa etária da população que precisa concluir o ensino fundamental e médio, percebemos o grande desafio do estado de garantir o direito à educação à classe trabalhadora, uma vez que a demanda é maior que a oferta. Destaca-se que o Pará é um dos estados brasileiros que apresenta um dos piores índices de atendimento ao ensino médio.

O fechamento de turmas de EJAI no ensino fundamental na Amazônia paraense se coaduna com dados de fechamento de turmas nas demais etapas de ensino, pois o estado do Pará, entre os anos de 2014 e 2017, totalizou cerca de 1.445 escolas fechadas (INEP, 2017). Destaca-se que muitas das escolas e/ou turmas fechadas nas redes de ensino do estado e dos 
municípios estão localizadas no campo e atingem a diversidade dos sujeitos que constroem o território paraense como quilombolas, indígenas, ribeirinhos, assentados.

$\mathrm{Na}$ intenção de identificarmos os sujeitos por faixa etária e por matrícula nas redes de ensino do estado e dos municípios que buscam atendimento na EJAI, no contexto da realidade do território da Amazônia paraense, é que apresentamos a Tabela 4 abaixo.

Tabela 4: Número de matrículas da Educação de Jovens e Adultos (EJA), por faixa etária, Pará $2013-2019$

\begin{tabular}{l|r|r|r|r|r|r|r|r}
\hline $\begin{array}{l}\text { Faixa } \\
\text { Etária/Ano }\end{array}$ & $\mathbf{2 0 1 3}$ & $\mathbf{2 0 1 4}$ & $\mathbf{2 0 1 5}$ & $\mathbf{2 0 1 6}$ & $\mathbf{2 0 1 7}$ & $\mathbf{2 0 1 8}$ & $\mathbf{2 0 1 9}$ & $\begin{array}{l}\text { Variação } \\
\mathbf{\%}\end{array}$ \\
\hline Até 14 anos & 4.559 & 3.048 & 1.850 & 1.204 & 923 & 914 & 757 & $-83,40 \%$ \\
\hline 15 a 17 anos & 63.683 & 60.677 & 56.213 & 50.188 & 44.199 & 41.498 & 37.866 & $-40,54 \%$ \\
\hline 18 a 19 anos & 39.842 & 39.901 & 38.780 & 36.591 & 33.587 & 32.850 & 29.008 & $-27,19 \%$ \\
\hline 20 a 24 anos & 46.939 & 45.269 & 43.593 & 42.253 & 40.962 & 39.994 & 35.316 & $-24,76 \%$ \\
\hline 25 a 29 anos & 28.751 & 25.778 & 22.984 & 20.399 & 20.068 & 18.399 & 16.941 & $-41,08 \%$ \\
\hline 30 a 34 anos & 23.658 & 21.277 & 18.272 & 15.930 & 16.133 & 14.769 & 13.412 & $-43,31 \%$ \\
\hline 35 a 39 anos & 17.192 & 16.004 & 14.219 & 12.345 & 12.889 & 12.254 & 11.260 & $-34,50 \%$ \\
\hline $\begin{array}{l}40 \text { anos ou } \\
\text { mais }\end{array}$ & 29.518 & 27.495 & 25.164 & 22.277 & 23.467 & 23.148 & 22.087 & $-25,17 \%$ \\
\hline \begin{tabular}{l} 
Total/ano \\
\hline
\end{tabular} & 254.142 & 239.449 & 221.075 & 201.187 & 192.228 & 183.826 & 166.647 & $-34,43 \%$ \\
\hline
\end{tabular}

Fonte: Elaborado a partir dos dados das sinopses estatísticas do Censo Escolar INEP de 2013 a 2019. (Obs.: A variação percentual foi calculada com a comparação do ano inicial com o ano final da série histórica)

A Tabela 4 nos mostra que a maior demanda de matrículas de EJAI nas redes de ensino encontra-se na faixa etária de 15 a 17 anos que, em 2013, correspondia as 63.683, sendo reduzida para 37.866 em 2019, o que corresponde em percentuais $40,54 \%$ a menos de matrículas. A segunda maior demanda de matrícula por faixa etária é de 20 a 24 anos com 46.939 em 2013, sendo reduzida para 35.316 em 2019 - em percentuais, 24,76\%. No geral, todas as faixas etárias que mais precisavam acessar a EJAI no estado do Pará tiveram redução nos números de matrículas. Destaca-se o total de redução envolvendo todas as faixas etárias que, em 2013, correspondia a 254.142 e passa para 166.647 , ou seja, $34,43 \%$ de matrículas para essas faixas etárias foram reduzidas.

A redução do atendimento na EJAI se evidencia também na oferta de matrículas no período de 2013 a 2019. A Tabela 5, abaixo, evidencia essa realidade.

Tabela 5: Número de matrículas por dependência administrativa (estadual e municipal) EJAI ensino fundamental e médio 
DOI: $10.12957 /$ teias.\%Y.50113

\begin{tabular}{|l|r|r|r|r|r|r|r|r||}
\hline \hline $\begin{array}{c}\text { DEPENDENCIA } \\
\text { ADMINISTRATIVA }\end{array}$ & $\mathbf{2 0 1 3}$ & $\mathbf{2 0 1 4}$ & $\mathbf{2 0 1 5}$ & $\mathbf{2 0 1 6}$ & $\mathbf{2 0 1 7}$ & $\mathbf{2 0 1 8}$ & $\mathbf{2 0 1 9}$ & $\mathbf{\%}$ \\
\hline Estadual & 94.403 & 91.367 & 85.415 & 78.022 & 72.218 & 68.016 & 61.112 & $-35,26 \%$ \\
\hline Municipal & 148.278 & 132.671 & 121.991 & 108.264 & 105.065 & 98.332 & 90.256 & $-39,13 \%$ \\
\hline Total & 242.681 & 224.038 & 207.406 & 186.286 & 177.283 & 166.348 & 151.368 & $-37,63 \%$ \\
\hline
\end{tabular}

Fonte: Censo Escolar INEP de 2013 a 2019.

A análise dos dados da Tabela 5 evidencia que o total de matrículas, envolvendo EJAI

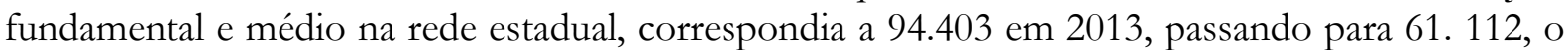
que representa em percentuais cerca de menos 35,26\% de matrículas. A realidade de redução de matrículas é percebida também na rede dos municípios paraenses que, em 2013, era de 148.278 e fora reduzido para 90.256 em 2019 - isso significa menos 39,13\% de matrículas nas redes municipais. O total de redução de matrículas nas duas redes de ensino chegou a 37,63\% em sete anos.

$\mathrm{Na}$ intenção de identificarmos a redução de matrículas por etapa de EJAI no ensino fundamental elaboramos a Tabela 6, abaixo.

Tabela 6: Matrículas rede estadual e municipal EJA ensino fundamental

\begin{tabular}{|l|c|c|c|c|c|c|c|c|}
\hline Dependência administrativa & 2013 & 2014 & 2015 & 2016 & 2017 & 2018 & 2019 & \% de variação \\
\hline Estadual & 44.948 & 42.617 & 36.943 & 33.575 & 27.874 & 25.575 & 21.755 & $-51,60 \%$ \\
\hline Municipal & 143.325 & 128.755 & 115.263 & 104.108 & 104.725 & 97.916 & 89.979 & $-37,22 \%$ \\
\hline Total & 188.273 & 171.372 & 152.206 & 137.683 & 132.599 & 123.491 & 111.734 & $-40,65 \%$ \\
\hline \hline
\end{tabular}

Fonte: Censo Escolar INEPA de 2013 a 2019

Os dados da tabela acima nos mostram que a redução de matrículas no ensino

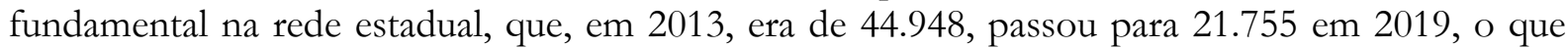
em percentual representa menos 51,60\% nas matrículas. Na esfera municipal, o total de matrículas passou de 143.325, em 2013, para 89.979 2019, um percentual de $37,22 \%$ a menos de matrículas. Dessa forma, o total de matrículas nessa etapa de ensino corresponde a uma redução de $40,65 \%$.

A Tabela 7, abaixo, revela o número de matrículas da EJAI no ensino médio, nas esferas estadual e municipal no Pará.

Tabela 7 - Matrículas estadual e municipal - EJA ensino médio

\begin{tabular}{|l|c|c|c|c|c|c|c|c|}
\hline $\begin{array}{c}\text { Dependência } \\
\text { administrativa }\end{array}$ & $\mathbf{2 0 1 3}$ & $\mathbf{2 0 1 4}$ & $\mathbf{2 0 1 5}$ & $\mathbf{2 0 1 6}$ & $\mathbf{2 0 1 7}$ & $\mathbf{2 0 1 8}$ & $\mathbf{2 0 1 9}$ & $\begin{array}{l}\text { \% de } \\
\text { variação }\end{array}$ \\
\hline Estadual & 47.620 & 47.003 & 47.321 & 42.934 & 44.344 & 42.441 & 39.357 & $\begin{array}{r}-17,35 \% \\
\hline \text { Municipal }\end{array}$ \\
\hline Total & $\mathbf{4 7 . 7 8 0}$ & 177 & 248 & 246 & 340 & 416 & 277 & $73,12 \%$ \\
\hline
\end{tabular}


No ensino médio, as matrículas na rede estadual correspondiam, em 2013, a 47.620, passando para 39.357 em 2019, cerca de $17,35 \%$ a menos. Curioso é que houve aumento de matrículas de EJAI médio na rede municipal que atendia 160 matriculas, passando para 277 em 2019, ou seja $73,12 \%$.

$\mathrm{Na}$ busca por identificarmos a redução no número de matrículas na EJAI nos 144 municípios paraenses, fizemos o levantamento nos dados oficiais e a Figura 1 abaixo nos mostra os percentuais de redução por município.

Figura 1 - Educação de Jovens e Adultos (EJA) nos 144 municípios do estado do Pará 2013 a 2019

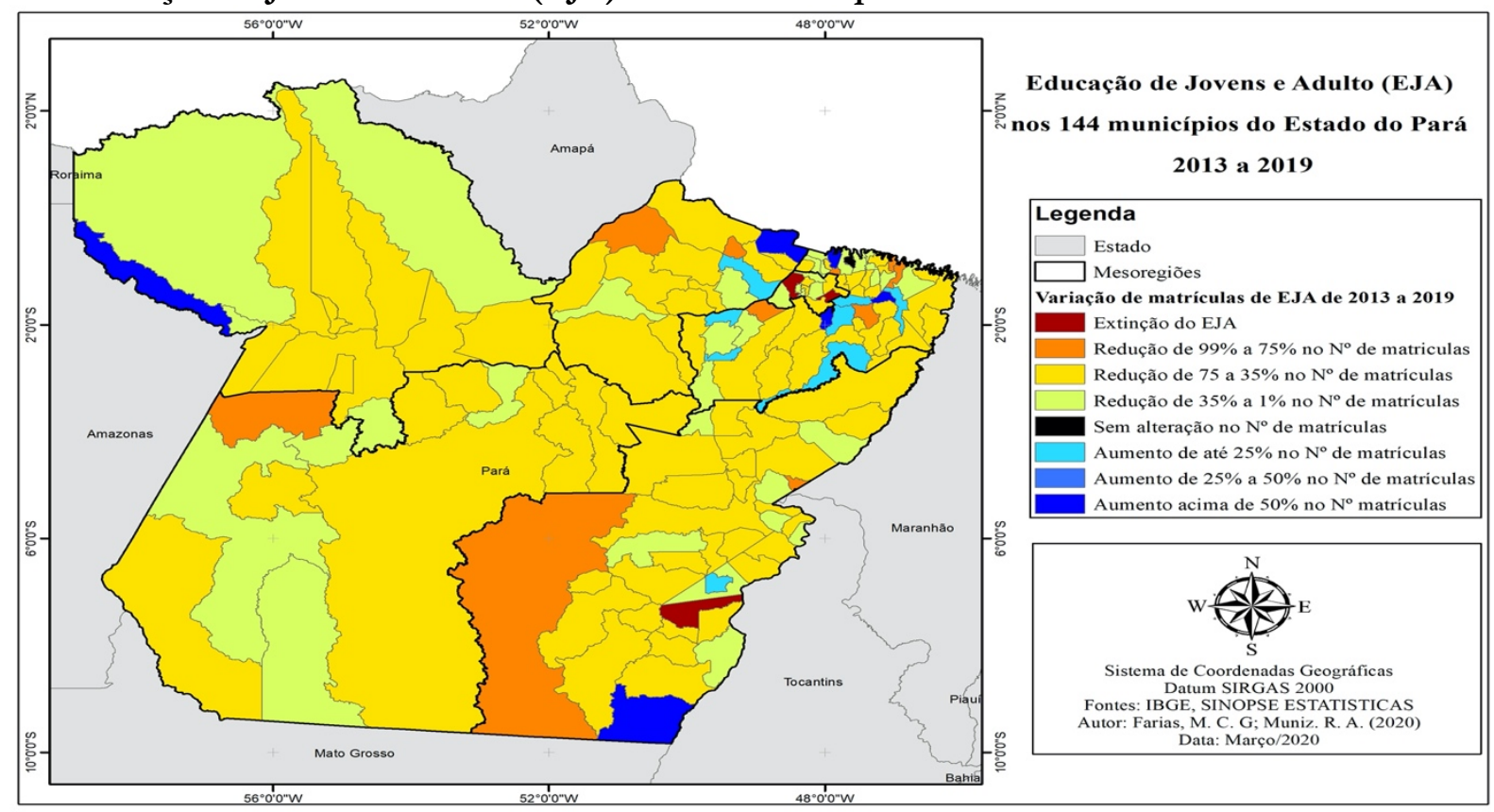

Fonte: IBGE 2019, CENSO ESCOLAR 2013-2019, SINOPSE ESTATÍSTICAS, 2019

Para melhor leitura das informações, optamos por agrupar em escala de cores o infográfico da Tabela 1, com os percentuais de matrículas nos municípios. Assim, de acordo com a legenda, podemos perceber que, de 2013 para 2019, três municípios paraenses extinguiram matrículas na EJAI. A cor laranja representa municípios em que a redução de matrículas atingiu $75 \%$ a $99 \%$. A cor amarelo destaca que a grande maioria dos municípios paraenses reduziram em $75 \%$ a $35 \%$ as matrículas em suas redes e ensino.

É importante destacar que, apesar de a maioria dos municípios terem reduzido o número de matrículas na EJAI, houve municípios que ampliaram a oferta de matrículas. Eles estão representados pela cor azul, respectivamente: em até $25 \%$; de $25 \%$ a $50 \%$; e acima de $50 \%$. Assim, identificamos os 15 municípios paraenses com aumento no número da oferta de matrículas de 2013 a 2019, são eles: Capanema, de 269, em 2013, passou para 284, em 2019 (+5,58\%); Concordia do Pará, de 877, em 2013, passou para 2.557 em 2019 (+175,03\%); Curuçá, de 129, passou para 250 (+93,80\%); Faro, de 122, passou para $264(+116,39 \%)$; Ipixuna do Pará, de 1.350, passou para $1.491(+10,44 \%)$; Limoeiro do Ajuru, de 223, passou para $273(+22,42 \%)$; 
Ourem, de 35, passou para $86(+145,71 \%)$; Ponta de Pedras, de 136, passou para $162(+19,12 \%)$; Rio Maria, de 437, passou para $600(+37,30 \%)$; Santa Luzia do Pará, de 463, passou para 475 (+2,59\%); Santana do Araguaia, de 1.698, passou para 2.859 (+68,37\%); São Domingos do Capim, de 877, passou para 933 (+6,39\%); São Miguel do Guamá, de 892, passou para 1.096 $(+22,87 \%)$; Sapucaia, de 353, passou para $403(+14,16 \%)$; Soure, de 58, passou para 107 $(+84,48 \%)$.

As análises dos dados oficiais das matrículas, no ensino fundamental e médio, nas redes do estado e dos municípios na EJAI, acompanham a tendência de queda nas matrículas nas demais etapas. O ensino fundamental regular do governo estadual teve redução de $21,18 \%$, e representa a diminuição de 48.368 matrículas, e no municipal diminuiu em 4,35\%, que equivale a 50.351 matrículas a menos na mesma série histórica de 2013 a 2019. Somados, esses números chegam a 98.719 matrículas a menos somente no ensino fundamental.

Outra análise para a maior redução de matrículas na EJAI fundamental, nas redes municipais de ensino, trata do fato de que, entre os anos de 1996 e 2006, ocorreu o período com maior quantidade de adesão das prefeituras: a política de municipalização do ensino fundamental do estado do Pará, que consistiu em transferência de matrículas, prédios escolares, professores, servidores da administração estadual para a administração dos municípios (ALVES, 2011). Os municípios paraenses passaram a atender grande número de matrículas nessa etapa de ensino tanto "regular" como nas modalidades como a EJAI.

\section{AS RESISTÊNNCIAS CONSTRUÍDAS POR MEIO DO MPEJA}

O Movimento Paraense de Educação de Jovens e Adultos (MPEJA) é composto por representantes dos movimentos sociais, professores e estudantes das instituições de educação superior, gestores, educadores e estudantes das redes públicas municipais e estadual da região. Integra o Fórum Paraense de Educação do Campo (FPEC) e foi constituído no ano de 2016, no município de Belém do Pará.

Freire (2012) destaca a importância da luta e da libertação da classe oprimida diante da realidade opressora. É necessário conhecermos os limites e contradições desta realidade e construímos uma ação libertadora que sirva de motor para a constituição da liberdade, da emancipação e da consciência para e com o outro na construção de uma sociabilidade com justiça e igualdade social.

Como um marco histórico em defesa da EJAI no Estado do Pará, que antecede a criação do MPEJA, destacamos o trabalho realizado por meio do curso de especialização lato sensu em Alfabetização de Jovens e Adultos para a Juventude na Amazônia, desenvolvido em duas versões: a primeira, em 2014, com total de 120 matriculados, e na segunda versão, no ano de 2015, foram ofertadas 80 vagas. Coordenado pelo Grupo de Estudos e Pesquisas em Educação do Campo (GEPERUAZ/ UFPa) e pelo Grupo de Estudo e Pesquisa em Educação de Jovens e Adultos e Diversidade na Amazônia (GUEAJA/UFPa/Bragança), o trabalho realizado foi pensado em defesa do direito à educação aos sujeitos da EJAI e da formação permanente de trabalhadores docentes que atuam na EJAI na cidade e no campo de diversos municípios do Estado. Tal curso foi uma proposta do Centro de Documentação e Memória em EJA na Amazônia da Universidade Federal do Pará-Instituto de Ciências da Educação - Campus Guamá e Faculdade de Educação do Campus de Bragança, no sentido de responder às demandas da Secretaria Estadual e das Secretarias Municipais de Educação (Região Metropolitana de Belém, Região 
Caetés e a Região Baixo Tocantins), no que concerne a formação continuada de profissionais de diferentes redes e movimentos sociais para atuarem como educadores no contexto regional (CORDEIRO, NEVES, 2017). As pesquisas oriundas deste curso se constituem também como ato de resistência e como luta pela construção do conhecimento, pela formação e pela politização dos processos, dos sujeitos, das condições e do tempo-espaço da EJAI na Amazônia.

O MPEJA vem se construindo na luta em defesa do direito à educação, ao acesso, à permanência e às condições de qualidade socialmente referenciada para jovens, adultos e idosos trabalhadores (as), na cidade e no campo. É uma busca pela educação dialógica e problematizadora, reconhecendo todos os envolvidos enquanto sujeitos históricos, que se humanizam entre si (FREIRE, 2012), em diálogo permanente com os conhecimentos construídos pela humanidade.

Assumimos e reafirmamos neste movimento, em nossas práticas e ações políticas, a compreensão de que a educação deve ser pública, gratuita, laica, socialmente referenciada e financiada pelo Estado como um direito histórico-social de todos os sujeitos da EJAI, já assegurada na legislação vigente, mas que ainda não é operacionalizada pelas gestões públicas estadual e municipais no nosso Estado.

O MPEJA também defende como princípios: 1) a Educação ancorada numa concepção de formação permanente, integral, humana, crítica e problematizadora (FREIRE, 2012); 2) condições de trabalho dignas aos docentes e aos estudantes; 3) políticas públicas de formação dos educadores que considere as especificidades da EJAI; 4) relação entre os conhecimentos escolares e os saberes culturais dos jovens, adultos e idosos; 5) ampliação da oferta de EJAI e não fechamento das escolas e turmas no turno da noite no campo e na cidade; 5) que o currículo e a situação da EJAI sejam discutidos nas instituições formadoras de ensino superior em todas as licenciaturas; 6) que o trabalho com a EJAI no campo considere os princípios da agroecologia; 7) a garantia do atendimento educacional aos jovens, adultos e idosos que estão em tratamento de saúde nos abrigos, em casas de apoio, hospitais e nos sistemas prisionais; 8) a garantia dos alunos com deficiência na EJAI tenham acompanhamento AEE (Atendimento Educacional Especializado) (CARTA, II SEMINÁRIO MPEJA, 2019).

Nos seminários do MPEJA e nas ações do movimento com os gestores educacionais, têm sido recorrentes as denúncias contra o fechamento de turmas de EJA no campo e na cidade; a diminuição da oferta nas redes municipais e estadual aliada ao avanço do Projeto Mundiar, que corresponde à aceleração da aprendizagem, presente na rede estadual de ensino no estado do Pará; ao Programa SEI (Sistema Educacional Interativo) em substituição ao SOME (Sistema de Organização Modular de Ensino), os quais vêm intensificando a precarização do trabalho docente, e contribuem para o desmonte da escola pública e para o fortalecimento da parceria público-privada, descaracterizando projetos protagonizados pelos sujeitos envolvidos com a EJAI, nas instituições de ensino do campo e da cidade, em que se incluem o Projovem Campo e Urbano e o ProEJA nas instituições de ensino.

Este coletivo vem se posicionando radicalmente contrário à Educação à Distância (EAD) na educação básica, inclusive na EJAI, porque nega a troca de saberes, a formação integral do ser humano, a relação professor-aluno no contexto da sala de aula; assim como a militarização das escolas nas redes de ensino e demais espaços educativos que ofertam EJAI. Essas proposições contribuem para: a desvalorização do trabalho docente, o sucateamento das escolas, fechamento de turmas, a diminuição da oferta na EJAI, as jornadas intensas de trabalho, o não cumprimento do piso salarial, a violência contra docentes e entre estudantes, a ausência de investimentos 
públicos no campo do esporte, lazer e cultura para todos os sujeitos da região. Tudo isso tem caracterizado o descaso dos governos municipais e estadual com a educação pública.

Podemos destacar, enquanto ações construídas pelo MPEJA, a realização de encontros, reuniões, seminários, rodas de conversas com estudantes, docentes e gestores da educação básica, pesquisadores (as) e movimentos sociais, engajados na luta em defesa da EJAI na cidade e no campo, nos municípios de Belém, Abaetetuba, Castanhal, Bragança, fortalecendo a bandeira da EJAI. Também apontamos os limites que esbarram no processo do movimento, as diversas frentes de trabalho que o conjunto dos integrantes possuem, quer seja na educação básica, no ensino superior, dentre outros, a imensa extensão territorial e a dificuldade de estar presente nos demais municípios do estado. Por outro lado, há a intenção de agregar os sujeitos a fim de consolidar a luta em defesa da EJAI no estado do Pará.

\section{CONCLUSÃO}

O contexto da EJAI na Amazônia Paraense vem sendo marcado pela negação dos direitos ao acesso e à permanência dos sujeitos que integram esta modalidade de educação. Os documentos analisados dos organismos multilaterais coadunam para "banir" a EJAI da educação básica, aprofundando as desigualdades de acesso à educação pública no Brasil e na Amazônia paraense (COSTA, HAGE, 2019). Há uma (pseudo)valorização da EJAI nos documentos analisados, falseando a realidade concreta e mantendo um discurso hegemônico de que a educação deve atuar para o acesso ao pleno emprego e para a redução da pobreza nos países (sub) e desenvolvidos.

O Brasil, segundo dados do IBGE (2019), tem pelo menos 11,3 milhões de pessoas analfabetas com mais de 15 anos, o que corresponde a 6,8\% de analfabetismo; no mundo, nesta mesma condição, há mais de 750 milhões de pessoas; no estado do Pará, esta realidade corresponde a 8,8\%. Na Amazônia paraense, a diminuição no atendimento, a partir do fechamento de turmas e a diminuição da oferta de matrículas no ensino fundamental e médio, vem se caracterizando como um aspecto forte de expropriação dos direitos da classe trabalhadora na cidade e no campo, como apresentado no decorrer deste estudo. A redução do atendimento da EJAI na Amazônia paraense, como ficou evidenciado nos dados do INEP, nos mostra que a diversidade socioterritorial dos sujeitos da classe trabalhadora é a maior prejudicada no direito à educação pela ausência de políticas públicas educacionais que considere a realidade heterogêneas dos sujeitos.

Em contraposição aos ataques à EJAI, há resistências que vêm sendo construídas pelo MPEJA, pelas instituições de ensino superior e da educação básica, pelos movimentos sociais e coletivos, pelos docentes e pesquisadores, dentre outros. As resistências vêm pautando a agenda em defesa desta modalidade de educação com o apoio da Ordem dos Advogados do Pará (OAB), do Ministério Público do Estado do Pará (MPEP), do Fórum Paraense de Educação do Campo (FPEC), da Cátedra Paulo Freire da Amazônia, do Núcleo de Educação Popular (NEP/UEPA), do Sindicato dos trabalhadores e trabalhadoras em educação pública do Estado do Pará (SINTEPP), dentre outros, que ajudam a fortalecer a luta em torno da EJAI.

Portanto, mediante à lógica hegemônica em torno das avaliações em larga escala; dos índices censitários das avaliações nacionais, orientados pelos organismos multilaterais; dos processos de exclusão que a EJAI na Amazônia paraense vem enfrentando, prejudicando estudantes e docentes como um todo, o esperançar que nos ensina Freire (2012) é de continuar 
lutando, denunciando e seguindo ombro a ombro na defesa da EJAI para os sujeitos da cidade e do campo, junto com todos aqueles e aquelas que se reconhecem enquanto sujeitos da EJAI, e defendem a educação pública, gratuita e socialmente referenciada.

\section{REFERÊNCIAS}

ALVES, Charles S. A politica de municipalização do ensino fundamental no estado do Pará a partir da ótica dos gestores estaduais da educação. Dissertação (Mestrado em Educação), PPGED, Universidade Federal do Pará, Belém, 2011.

ANTUNES, Ricardo. Adeus ao trabalho? Ensaio sobre as metamorfoses e a centralidade do mundo do trabalho. 15a edição. São Paulo: Cortez; Campinas: Editora da Unicamp, 2005a.

BRUNS, B.; EVANS, D.; LUQUE, J. Achieving World-ClassEducation in Brazil: The Next Agenda. World Bank Publications, cap. 3, 2011. Disponível em http:// web.worldbank.org. Acesso em 20 mar. 2020

CORDEIRO, Georgina N. K.; NEVES, Joana D’Arc de V. Diálogos sobre a Juventude na Educação de Jovens e Adultos na Amazônia Paraense: perspectivas e práticas. Belém-PA: Samauma Editorial, 2017.

COSTA, Maria da Conceição dos S.; HAGE, Salomão A. M. A Educação de Jovens e Adultos na agenda do capital: uma análise sobre os documentos oficiais da Unesco e do Banco Mundial. In: DIAS, Alder de S.; GUIMARÃES, André R.; NOVAIS, Valéria S. de M. (org.). Pensamento freiriano e educação de jovens e adultos na Amazônia. 1. ed. Curitiba: Appris, 2019.

BOTTOMORE, Tom (org.). Dicionário do pensamento marxista. Rio de Janeiro: Jorge Zahar, 1988.

CONCEIÇÃO, Darinêz de Lima. Práticas Educativas Dialógicas como Referência para Re-conceituar a Educação de Jovens e Adultos: estudo de uma experiência do PROEJA no Instituto Federal do Pará, Campus de Castanhal. PPGED UFPA, 2016.

EVANGELISTA, Olinda. Apontamentos para o trabalho com documentos de política educacional. In: Colóquio a pesquisa em trabalho, educação e políticas educacionais, 1, 2009, Belém. Anais Belém: UFPA, 2009. $\quad$ Disponível em http://louderdesign.net/gepeto/producao/view.download/120.html. Acesso em 29 jan. 2020.

FREIRE, Paulo. Pedagogia do oprimido. Edição especial. Rio Janeiro/São Paulo: Nova Fronteira, 2012.

GONÇALVES, Carlos W. P. Amazônia, Amazônias. São Paulo: Contexto, 2005. 179 p.

HAGE, Salomão; BARROS, Oscar. Currículo e Educação do Campo na Amazônia: referências para o debate sobre a multisseriação na escola do campo. ESPAÇO DO CURRÍCULO, v. 3, n. 1, p. 348-362, mar./set. 2010.

INEP/MEC. Ministério da Educação. Relatório Brasil no Pisa, 2019.

INEP - INSTITUTO NACIONAL DE ESTUDOS E PESQUISAS EDUCACIONAIS ANÍSIO TEIXEIRA. Sinopse Estatística da Educação Básica 2018. Brasília: INEP, 2019. Disponível em http://portal.inep.gov.br/sinopses-estatisticas-da-educacao-basica Acesso em 03 mar. 2020.

KOSIK, K. Dialética do concreto. (Trad. Célia Neves e Alderico Toríbio). 2. ed. Rio de Janeiro: 1976.

MEC/SESA. Ministério da Educação. Planejando a Próxima Década Conhecendo as 20 Metas do Plano Nacional de Educação/ Secretaria de Articulação com os Sistemas de Ensino (MEC/Sase), 2014. 
MORENO, Ana Carolina. Em uma década, Brasil perde um terco das escolas para adultos com aulas de ensino fundamental. Disponível em https://g1.globo.com/educacao/noticia/2019/04/06/em-umadecada-brasil-perde-um-terco-das-escolas-com-aula-do-ensino-fundamental-para-adultos.ghtml. Acesso em 25 mar. 2020.

OLIVEIRA, Lorena M. M. de; HAGE, Salomão A. M. A socioterritorialidade da Amazônia: as políticas de educação do campo. Ver a Educação, v. 12, n. 1, p. 141-158, jan./jun. 2011.

PAIVA, Jane; MACHADO, Maria M.; IRELAND, Timothy (org.). Educação de Jovens e Adultos: uma memória contemporânea, 1996-2004. Brasília: Secretaria de Educação Continuada, Alfabetização e Diversidade do Ministério da Educação: Organização das Nações Unidas para a Educação, a Ciência e a Cultura, 2007.

PINTO, Lúcio F. In: SCHMINK, Marianne; WOOD, Charles H (org.). Conflitos Sociais e a Formação da Amazônia. (Trad. Noemi Miyasaka e Raimundo Moura). Belém: Ed. UFPA, 2012.

SANTOS, Milton. O dinheiro e o território. GEOgraphia, Rio de Janeiro, Ano 1. n. 1, 1999.

SHIROMA, E. O.; CAMPOS, R. F.; GARCIA, R. M. C. Decifrar textos para compreender a política: subsídios teórico-metodológicos para análise de documentos. PERSPECTIVA, Florianópolis, v. 23, n. 2, p. 427-446, jul/dez. 2005. Disponível em http://www.ced.ufsc.br/nucleos/nup/perspectiva.html. Acesso em 20 mar. 2020.

SHIROMA, E.; EVANGELISTA, O. Luzes que desiluminam: uma análise dos slogans na política educacional. In: EVANGELISTA, O (org.). O que revelam os slogans na politica educacional. Araraquara, SP: Junqueira\&Marin, 2014.

UNESCO. Fórum Mundial de Educação 2015. Declaração de Incheon. Organização das Nações Unidas para Educação, a Ciência e a Cultura. Disponível em http://unesdoc.unesco.org/images/0023/002331/233137POR.pdf. Acesso em 20 mar. 2020.

UNESCO. Relatório de Monitoramento Global de Educação - migração, deslocamento e educação: construir pontes, não muros. Organização das Nações Unidas para Educação, a Ciência e a Cultura, 2019.

VENTURA, Jaqueline P. Educação de Jovens e Adultos on Educação da Classe Trabalhadora? Concepções em disputa na contemporaneidade brasileira. 302 f. Tese (Doutorado em Educação). Programa de Pós-Graduação em Educação, Universidade Federal Fluminense, Rio de Janeiro, 2008.

Submetido em abril de 2020 Aprovado em dezembro de 2020

\section{Informação das autoras}

Maria da Conceição dos Santos Costa

Universidade Federal do Pará - Instituto de Ciências da Educação - Faculdade de Educação Física

E-mail: concita.ufpa@gmail.com

ORCID: http://orcid.org/0000-0002-8256-068X

Link Lattes: http://lattes.cnpq.br/6147701581227207

Maria Celeste Gomes de Farias 
Secretaria de Estado de Educação - Pará

E-mail: celechar@hotmail.com

ORCID: http://orcid.org/0000-0001-6952-0942

Link Lattes: http://lattes.cnpq.br/9113215245422371

Darinêz de Lima Conceição

Universidade Federal do Pará - Faculdade de Educação Física - Campus de Castanhal

E-mail: darynez@yahoo.com.br

ORCID: http://orcid.org/0000-0003-1390-4159

Link Lattes: http://lattes.cnpq.br/0079505725456922 